\title{
An Environment-Friendly Conductive Concrete
}

\author{
Xin $\operatorname{Tian}^{1,2}, \mathrm{Hu} \mathrm{Hu}{ }^{1,2} \&$ Bin $\mathrm{Chen}^{1}$ \\ ${ }^{1}$ Architecture Engineering School, Yunnan Agricultural University, Kunming, China \\ ${ }^{2}$ Energy Saving and Reduction Inspection \& Research Engineering Center, Yunnan Agricultural University, \\ Kunming, China \\ Correspondence: $\mathrm{Hu} \mathrm{Hu}$, Architecture Engineering School, Yunnan Agricultural University, Kunming, China. Tel: \\ 86-180-6486-4334. E-mail: 76huhu@163.com
}

Received: June 1, 2012 Accepted: June 21, 2012 Online Published: July 6, 2012

doi:10.5539/esr.v1n2p185 URL: http://dx.doi.org/10.5539/esr.v1n2p185

Foundation-supported program: The project of scientific research foundation of the Education Department of Yunnan Province (2010C231)

\begin{abstract}
This article describes that the author, through the continuous exploration of improving and optimizing the preparation method and process of conductive concrete, has found a kind of environment-friendly conductive concrete with high conductive property, simple preparation method and process, low cost and convenient application in the construction site.
\end{abstract}

Keywords: conductive concrete, preparation method and process, green and environment-friendly

\section{Introduction}

The property and mixed method of conductive concrete will vary with the conductive components (such as: graphite, steel slag, stainless steel fiber and carbon fiber) mixed in the concrete. The different conductive component, mixing proportion and preparation process not only determine the electric property of conductive concrete, but also affect the convenience and cost control in their late application. Today, with more and more attention to the green and environmental protection, account will be taken into the pollution of the materials mixed in the concrete to the environment. Otherwise, the conductive concrete, even it is of high property, will not be allowed to use.

The conductive property is decisive to the properties and application value of the conductive concrete. A simple preparation process will produce the convenience of application. Whether the conductive concrete is favorable for the green and environmental protection will reflect a responsible attitude to the nature and society. Therefore, high property, practicality and environmental protection has been the principle and direction the author adheres to his research and exploration of preparation method and process of conductive concrete.

\section{Improving the Conductive Property of Concrete}

The conductive property is the first element of conductive concrete. The material resistivity is an index which reflects the conductive property of the concrete. In order to obtain the resistivity as low as possible, the author experimented many different kinds of and different specifications of conductive materials, adopted different proportions and preparation processes, finally found a relatively reasonable optimization scheme after balancing the cost factors.

\subsection{The Conductive Concrete with Graphite as Conductive Material}

Graphite is a kind of good conductive material. It is widely used in the areas related to electric conduction and also a popular material used in the conductive concrete due to its good conductivity, stable property, wide material source and no pollution to environment. The author make some comparison tests in different proportions by taking respectively the soil shape common graphite samples with carbon content more than $80 \%$ and the flaky high grade graphite samples with carbon content more than $95 \%$ and fineness of 500 mesh. See Figure 1 Comparison of Different Graphite for the test result.

We can see from the figure, the conductive property of the high grade flaky graphite with high carbon content 
and high fineness has the conductive property higher than that of the soil shape common graphite with low carbon content, and the conductive property of the concrete will improve with increase of the graphite proportion. However, the graphite inherent lubricity greatly decreases the strength of the concrete with high graphite proportion and the cost of the concrete greatly increases with increase of the graphite proportion. Obviously, it is not an ideal way to use the high price and high grade graphite and raise the graphite proportion in the concrete to improve the conductive property, the comprehensive property and economic result(it is not an ideal way to improve the conductive property, the comprehensive property and economic result by using the high price, high grade graphite and raising the graphite proportion in the concrete).

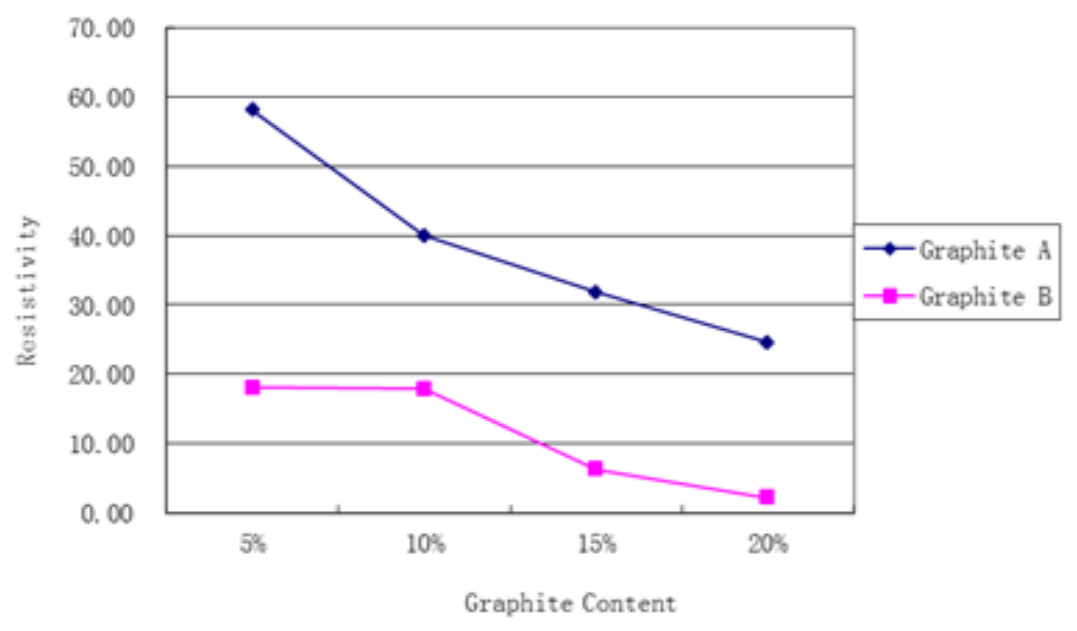

Figure 1. Comparison of Different Graphite

\subsection{Composite Conductive Concrete with Carbon Fiber}

The author tried to use the composite conductive concrete with a new conductive fiber material as the dominant material and other materials as the auxiliary ones for improving the conductive property of the conductive concrete since the conductive concrete mixed with pure graphite cannot get the satisfactory conductive property, strength and economic result. As it easily forms the conductive channel between the materials, the conductive fiber material can evidently improve the conductive property of the conductive concrete, as shown in Figure 2.

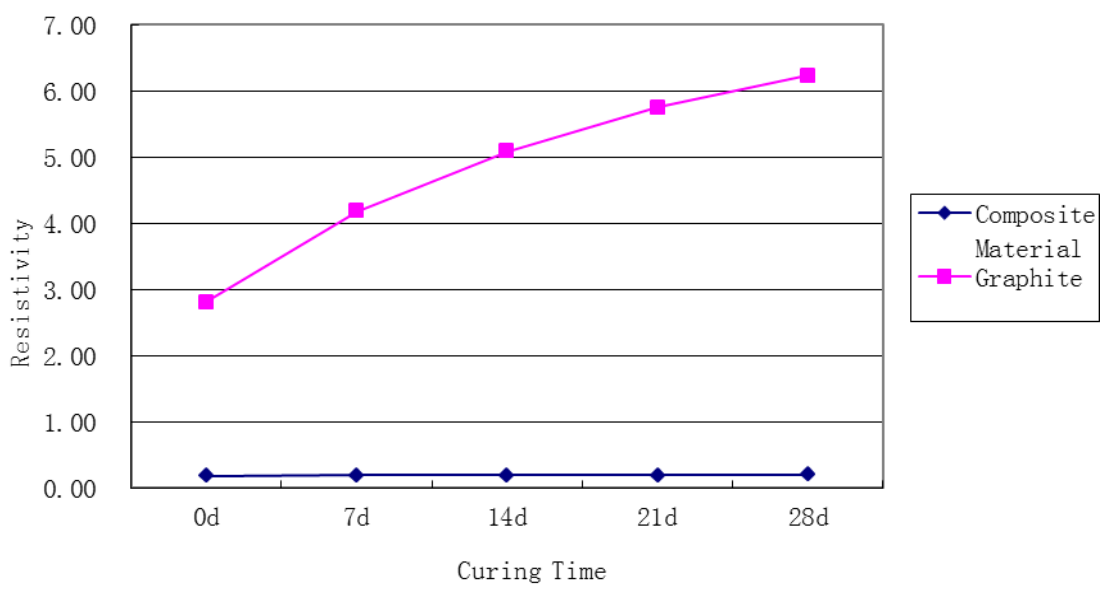

Figure 2. Comparison of Graphite and Composite

Figure 2 Comparison of Graphite and Composite Material shows, the graphite used for comparison is the high grade flaky graphite with $95 \%$ carbon content and in the proportion of $15 \%$. According to the used material and its proportion, the conductive concrete is the very good graphite conductive concrete. But compared with the 
composite conductive concrete, the conductive property of the graphite conductive concrete is evidently not in the same order of magnitude. Moreover, the resistivity of the graphite conductive concrete gradually will rise with the curing time extending, but the resistivity of the composite conductive concrete changes slightly and its conductive property is very stable. This is a big advantage of the composite conductive concrete, that is, the concrete already has a good and stable conductive property in its initial setting stage. Although the graphite conductive concrete has a relatively good conductive property in its initial setting stage, the conductive property will gradually decrease and finally reach a stable value as time goes on. When the conductive concrete is used as the resistance reducing agent, the composite conductive concrete can be used for the effect test soon after pouring. The test values measured in this stage are basically consistent with those measured after setting of concrete. This can not only improve the work efficiency and shorten the work cycle, but also increase the economic benefit.

\section{Exploration on Improving Process and Practicality}

Although the conductive fiber material can greatly improve the conductive property of the concrete, the original preparation process makes it very difficult to apply such fiber material in the construction site. In order to bring it into utmost play, the fiber material must be evenly distributed in the concrete, which needs to be accomplished by adding dispersant. The dispersant can be dissolved only in the high temperature water. It is not very difficult to solve the problem in the lab because it is a small-batch test. But in the construction site, to dissolve the dispersant in the high temperature water will be a Gordian knot. If this problem is not solved, the wide application of the fiber material in the engineering practice will be certainly limited.

Finally, the author has found a new conductive fiber material. Compared with the original material, the anti adhesive property of such new fiber material has been greatly improved. First, such fiber material is physically mixed with the superfine flake graphite and the lubricity and diffusibility of graphite will reduce the adhesive property among fibers to the minimum. During preparing the concrete, the stone powder material like silicon ash is also used for dispersing fiber again. The stone powder material has much lower cost than silicon powder and has wide sources. The author has finally solved the problems of fiber agglomeration and uneven distribution by using a physical dispersing method in place of the traditional chemical dispersing method, thus, has laid a good foundation for convenient application of such fiber material in the engineering practice.

\section{Environment-friendly Resistance-reducing Material}

In the grounding construction of the electric power system (such as substation and wind farm) and the special buildings (such as gas station), a number of resistance-reducing agent is used to reduce the grounding resistance because of high requirement of grounding resistance. Both the traditional chemical resistance reducing agents and the physical resistance reducing agents widely used now have a problem that themselves are not able to solidify and then run off, thus it cause great harm to environment. Firstly, these resistance reducing agents contain heavy metal and other chemical components harmful to environment. They will flow to the deeper soil with water in the soil to pollute the soil and water sources. Secondly, the running off of resistance reducing agent makes the soil which originally wraps the grounding electrode superseded by general soil, so severely reduces the resistance reducing effect. In this case, the grounding resistance value will rebound year after year and cannot reach the design standard. In addition, the traditional chemical resistance reducing agents have certain corrosion to the grounding electrode, which will make the grounding electrode out of action due to rusting at last, and make grounding not to be up to standard.

The composite conductive concrete prepared by the author has reached and even exceeded many resistance reducing agent materials in the aspect of conductive property (The conductive property of the composite conductive concrete prepared by the author has reached and even exceeded those of resistance reducing agent materials) (According to the national standard, the resistivity of the resistance reducing agent is $<5 \Omega \cdot \mathrm{m}$ and the resistivity of composite conductive concrete prepared by the author is $<0.5 \Omega \cdot \mathrm{m}$.) and at the same time, the greatest advantage lies in the environmental protection. No materials used in the composite conductive concrete contain the substance harmful to environment. This is particularly important today when the state energetically promotes the policy of environmental protection. Due to its own setting property, such conductive concrete does not run off in the soil as time goes on, does not corrode but protect the grounding body and can play a long and stable role in reducing resistance and also reduce the cost of its later use and maintenance. So it is an ideal green and environment-friendly resistance reducing material.

\section{Conclusion}

1) High carbon content and high fineness flaky graphite is favorable for improving the conductive property of the conductive concrete. 
2) The composite conductive concrete which takes new conductive fiber as the dominant material and other materials as the auxiliary material has much higher conductive property and more stable performance than the graphite conductive concrete.

3) The adoption of the new materials and the new process is an important guarantee for convenient application of the conductive concrete in the engineering practice.

4) Whether the conductive property or the environmental property, the new type conductive concrete is a very ideal resistance reducing material. It can be used in the grounding system in place of the traditional resistance reducing agent.

In the process of preparation and exploration of the conductive concrete, a great number of data and also a satisfactory result have been obtained through both continuous adjustment of materials and mixing proportion and continuous process improvement. The good conductive property and environmental property of the new type conductive concrete has laid solid foundation of its future application in many areas.

\section{References}

Chen, B., Wu, K. R., \& Yao, W. (2002). Studies on Electrical Conductivity of Fiber Reinforced Concrete and its Application. CONCRETE, 7, 23-27.

Cheng, L. H., Meng, H. R., \& Xi, Y. L. (2006). Application of short carbon fibers in concrete. CONCRETE, 4, 29-31.

Deng, S. C., \& Li, S. C. (2003). Studies and analyses on concrete electric resistance oefficient. CONCRETE, 3, $10-12$.

Farhad, R., Gordon, B. B., Jerry, A. Y., \& Jong, S. L. (2001). Volumeelectrical Resistivity of Carbon Fiber CementComposites. ACI Materials Journal, 98(1), 25-35.

Jiang, Z. W., Sun. Z. P., \& Wang, X. Y. (2000). Conductive Concrete Technology. CONCRETE, 9,55-58.

Li, G. J., Zheng, X. M., \& Wang, B. (2006). Experimental Study on Electrical Conductivity of Carbon Fiber Reinforced Concrete. Journal of Jiamusi University (Natural Science), 3, 457-459.

Lu, Z. H., \& Zhang, Y. F. (2009). Study on the Compressive Strength and Electrical Conductivity of Carbon Fiber-slag Concrete. Science Technology and Engineering, 9, 2510-2512.

Mao, Q. Z., Zhao, B. Y., Shen, D. R., \& Li, Z. Q. (1996). Study on the Compression Sensibility of Cement Matrix Carbon Fibre Composite. Acta Materiae Compositae Sinica, 4,8-11.

Park, S. B., Lee, B. I., \& Llim, Y. S. (1991). Experimental study on the engineering properties of carbon fiber reinforced cement composites. Cement and concrete research, 21(4), 589-600. http://dx.doi.org/10.1016/0008-8846(91)90110-4

Shen, G., \& Dong, F. Q. (2004). Performance Research on Carbon Fiber Conductive Concrete. HIGHWAY, 12, 178-182.

Sherif, Y., Christopher, Y. T., David, F., \& Bing, C. (2000). Conductive Concrete Overlay for Bridge Deck Deicing Mixture Proportioning, Optimization, and Properties. ACI Materials J., 97(2), 172-181.

Sun, J. G., Yang, W. D., \& Zhang, B. (2007). Research of Electrical Conductivity of Carbon Fiber Reinforced Concrete Based on Uniform Design. Journal of Dalian Nationality College, 1, 20-23.

Toutanji, H. A., EI -Torehi, T., \& Tatz, R. N. (1994). Strength and reliability of carbon - fiber- reinforced cement composites. Cement and concrete composites, 16(1), 15-21. http://dx.doi.org/10.1016/0958-9465(94)90026-4

Xin, T., \& Hu, H. (2012). Test and Study on Electrical Property of Conductive Concrete. 2012 International Conference on Structural Computation and Geotechnical Mechanics.

Zhang, W. F., Ma, C. H., Zhao, W. Y., Cai, Y. J., \& Zhu, D. R. (2009). Electrical Conductivity of Graphite Conductive Concrete. Journal of Daqing Petroleum College, 1, $72-77$. 